\title{
Exploration on Low-Carbon Development Incentive System of Hainan Hotel Industry
}

\author{
Huali Li \\ School of tourism and civil aviation management, Haikou College of Economics, Haikou Hainan, \\ 571127, China
}

Keywords: Hainan, Hotel industry, Low-carbon, Incentive system.

\begin{abstract}
Hotel industry as a pillar industry in Hainan tourism profession in recent years the pace of development is also relatively fast. However, in Hainan to strengthen the process of building an ecological province, low-carbon development of the hotel industry, there are still some problems, the management level is relatively low, there is a serious waste of energy and resources. It is therefore imperative for the development of low-carbon incentives Hainan hotel industry research, practical to take certain measures to promote the process of building a low-carbon Hainan hotel industry.
\end{abstract}

\section{Introduction}

In recent years, China's low-carbon development of the hotel industry is still in its infancy, the government incentives for the hotel industry conditions generally confined to the proposed terms of energy saving, unable to effectively mobilize hotel industry energy conservation initiative. Thus the new era, in order to further enhance the level of carbon hospitality industry, to develop low-carbon development strategy more in line with the development of the hotel industry in Hainan, should the current low-carbon development in Hainan hotel industry is analyzed, and then the actual situation targeted measures to provide appropriate guidance and protection for low-carbon construction hotel industry. The only way to effectively promote low-carbon development process in Hainan hotel industry in the new period is the contribution of the respective strength of building an ecological province of Hainan.

\section{Low-carbon hotel and hotel low-carbon development}

\section{Low carbon hotel.}

China's low carbon hotel is a low-carbon economy practice in the hotel industry. In the actual process of building a low carbon hotel requirements in economic management fully implement carbon management philosophy, and make full use of low-carbon technologies to minimize emissions of carbon dioxide in the actual course of business hotel, the hotel industry can effectively promote sustainable development. And Saving the hotel there are some differences, low-carbon hotel in the development process should reduce the emphasis on carbon dioxide emissions and the actual emissions of carbon dioxide as a standard, the hotel management activities proposed mandatory requirements [1]. In the specific construction process, the construction of low-carbon focus is on the hotel's advanced low-carbon technologies and the introduction of low-carbon management philosophy, and to further enhance the management level of carbon aim is to gradually reduce the energy consumption of the hotel, the hotel to minimize carbon emissions, to carry out environmental protection work contribution corresponding strength. It can be said that in the current background of building a low carbon economy, low-carbon future hotel building is the main development direction of the hotel industry, the hotel building is bound to low-carbon social image of the hotel in the future course of development, long-term development and lasting competitiveness generate a specific impact. It is therefore imperative to strengthen the focus on low-carbon hotel construction work, provide the appropriate safeguards for the sustained and healthy development of Hainan hotel industry. 


\section{Hotel low-carbon.}

Chinese Characters in our interpretation, "of" mainly used after nouns and adjectives, specifically expressed its transition to a certain state or nature. It can be seen that the construction of Hainan hotel low-carbon low-carbon development is to promote the hotel, the hotel's low-carbon development in Hainan hotel is truly converted to the corresponding low-carbon measures taken during the hotel, which is Hotels carbon implementations [2]. In contrast, low-carbon development of the hotel has a certain complexity and systematic, we need to implement low-carbon concepts and ideas in various aspects of the actual design of the hotel, management, service and construction, the hotel building in order to promote low-carbon targets. In the current social background, the hotel's low-carbon having diverse forms of development, need hotels with their own situation in the management process to take appropriate way to achieve, and the same hotel at different period of development should be combined with the background of low-carbon technology implementation of appropriate adjustment, provide protection for low-carbon development of the hotel industry, the practical realization of low-carbon development and management objectives in the construction process.

\section{Low-carbon development status of Hainan hotel industry}

\section{The hotel industry has great energy consumption in the development.}

The current assessment star hotel industry by the impact of a number of star hotels of Hainan in the development process in order to improve quality, the pursuit of higher interests, the pursuit of luxury in the decoration, resulting in an average energy consumption of the building the hotel industry has remained at a high level . While under construction in Hainan international tourism island's social background, with the further increase in tourist and hotel industry has also been some development, so the hotel industry and international development in order to adapt the image of Hainan, room design pursuit of internationalization, and the lack of effective use of wind, solar and other ecological energy in the actual construction process, not only will result in a waste of natural resources, but also increase the hotel's carbon emissions [3]. Thus, Hainan hotel industry in the development process has gradually become Hainan energy polluters, thus building an ecological province of Hainan must pay greater attention to the construction of low-carbon hotel, fully tap its huge potential for low-carbon development, Hainan hotel industry effectively promote low-carbon building process.

\section{The low carbon management quality of Hainan hotel industry is poor.}

Related research shows, most of Hainan hotel industry to respond positively to the call of the country in terms of energy conservation made some efforts to implement energy saving measures are also located in the corresponding follow-up and implementation, but in essence, hotels Although energy conservation have begun to realize the importance of low-carbon construction of the hotel, and had taken appropriate measures to enhance the hotel hoping to carbon level of the building, but due to lack of staff awareness of low-carbon correct hotel, even part of the work staff generally only heard on the news media over the network or low-carbon economy, coupled with poor management of the hotel, to a certain extent, leading to energy saving and low-carbon work hotel construction work is not satisfactory, severely limit the hotel industry Low-carbon development process. Therefore Hainan hotel industry should pay attention to management, employees on the basis of full publicity and education on the organization of employees trained in the hotel building low-carbon, prompting employees to assist low-carbon hotel building work in practice, and effectively enhance the hotel industry low-carbon management level.

\section{Incentive system of Hainan hotel industry low-carbon development}

Government departments should further strengthen policy guidance and behavior.

Hainan hotel industry in order to achieve low-carbon development, we must in the actual construction process with clear guidance and support system as the basis, so in order to further alleviate the current development status of the hotel industry of low-carbon, low-carbon development of the hotel industry for effective incentives, Government departments should implement the right to 
guide the consumer market, develop appropriate norms and standards, and promote the development of low-carbon processes hotels Hainan province. In actual operation, the Hainan provincial government departments should be combined with the actual situation of the introduction of appropriate incentives to implement the right hotel guide, hotel really encourage low-carbon innovation in the actual management process, guided hotel uses renewable energy [4]. At the same time, the government should focus on low-carbon hotel building needs, develop appropriate emission standards, energy efficiency standards and specific criteria for low-carbon hotel building, and incorporate these standards into the star hotel assessment standards, promote low-carbon hotel construction standardization and standardized development. In terms of policy support, the relevant government departments should also be able to promote the implementation of low-carbon development process hotel tax and financial policies, and further increase the energy service companies to support efforts to improve the relevant certification system, the real low-carbon development of the hotel industry to pave the way to a low-carbon incentives for the construction of the hotel, thereby promoting low carbon levels Hainan hotel industry in support of the Government gradually enhanced to provide appropriate protection for building an ecological province of Hainan.

\section{Establish a sound legal system for hotel low-carbon.}

Our judiciary combined with Hainan hotel low-carbon construction conditions develops related laws and regulations, not only can promote the development of low-carbon hotel based on evidence and to carry out the work according to the law, but also for the construction of low-carbon hotel create a positive and healthy environment. However, it can be seen from the relevant investigation, our country Hainan has not yet worked out with the hotel industry, low-carbon construction-related legal system, resulting in the construction of low-carbon Facing the lack of appropriate legal basis for the new environment, or even to carry out the work no laws, has seriously hampered the effectiveness of low-carbon technology [5]. Therefore Hainan relevant government departments should formulate laws and regulations applicable to the hotel industry low-carbon methods province construction in accordance with relevant provisions of national law, provide legal support to low-carbon hotel construction. Meanwhile, the government departments should also be combined resource characteristics Hainan appropriate introduction to the hotel industry can be a low-carbon development has played a role in promoting industry standards, provide the appropriate specifications for the construction of low-carbon Hainan hotel industry, and promote the Hainan Hotel the process of building a low-carbon industry, to build a harmonious society contribute appropriate force.

\section{The hotel sector should set up a low-carbon building professional committee.}

Hainan hotel industry in the development process, in order to respond to the call of the context of national low-carbon economy, and actively promote the development of low-carbon hotel, should also be on the basis of the original Tourist Hotels Association of Professional Committee, the working set of low-carbon low-carbon Committee for Work for hotel staff to implement carbon management training, to strengthen the exchange of information infrastructure and the construction of low-carbon products of interaction between the hotels and the like, for the development of low-carbon Hainan hotel industry to provide the appropriate support. Meanwhile, after a low-carbon Work Commission, which can be appropriate to strengthen exchanges and cooperation with energy Services Company, to create an effective information platform for the construction and development of low-carbon hotel for the initial participation of low-carbon building activities provide hotel support and learn from success stories, promote low-carbon construction Hainan hotel industry scale development. In addition, the Professional Committee of carbon can also be on the current Hainan hotel low-carbon development status investigation and analysis to understand the hotel in strengthening low-carbon construction process problems and difficulties exist development offers some help and support, provide the appropriate safeguards for the hotel low-carbon construction.4. Strengthen the publicity and guidance inside the hotel

For the hotel of their production and consumption of products have a certain identity, their own low-carbon conscious consumers in the consumption process, the hotel's low-carbon measures taken by the actual degree of cooperation will have a corresponding impact on the economic benefits of the hotel. Thus, the initial implementation of low-carbon construction of the hotel must go through 
proper education, consumer awareness of low-carbon culture, science and impact of the implementation of consumer behavior. Related research shows, in Hainan tourist crowds, only a small number of people entering the hotel, will actively cooperate with the low-carbon consumption measures taken to hotels, adhere to energy conservation attention in the course of living, but also a majority of people said that if reasonable price, willing to participate in the respective low-carbon consumption. Thus, as long as the hotel's carbon consumption to develop a reasonable price, and ensure the quality of service the hotel, most consumers would be willing to accept the corresponding low-carbon services to contribute to the development of low-carbon economy. Meanwhile, the hotel in the development of appropriate measures on the basis of the price of green, low-carbon marketing can also be implemented as a willingness to participate in low-carbon low-carbon plan of customer membership system to ensure that their stay at the same time other parts of the country must be able to enjoy this hotel offer services, and effectively promote the construction and development of low-carbon hotels, provide protection for low-carbon construction hotel industry.

\section{Attach importance to hotel low-carbon technology talents training.}

In the new period, strengthen the construction of low-carbon hotel in Hainan not only requires a lot of money for support, but also must have the guidance of a professional management staff of carbon hotel operation and management of the implementation of scientific work. However, there is a significant talent shortage phenomenon in our country Hainan hotel industry low-carbon construction process, has produced limited impact on low-carbon development of the hotel industry. For the hotel industry, low-carbon construction professionals, its hotel management should not only be familiar with the various departments in the process of work flow, have a certain quality of hotel management, but also should have corresponding low-carbon technologies and related management knowledge, capable of binding the hotel's actual development and construction of low-carbon, low-carbon construction of the hotel for further selection and reasonable measures. Thus the government, universities, hotels should jointly strengthen personnel training mechanism, adjust educational programs as soon as possible, to meet the real train hospitality industry development of low-carbon compound talents, provide the appropriate human resources and support for the construction of low-carbon hotel. At the same time, the hotel staff themselves should also recognize that the current low-carbon development of the hotel industry demand for talent, then combined with the actual needs of hotels and active participation of social organizations in relevant sectors of education and training activities, and gradually improve their overall quality, tap potential, thus on its own contribution to the respective positions of strength for the low-carbon development of the hotel industry in achieving personal development of the hotel industry to promote low-carbon development process.

\section{Conclusions}

In summary, in Hainan Province, the implementation of the process of building an ecological province, the construction of low-carbon hotel plays an extremely important role, so in the New Hainan Province, the relevant departments should strengthen the construction of Hainan hotel low-carbon attaches to the work actively with the current hotel Low carbon construction status from the government, industry, the hotel itself and the staff of several aspects to take appropriate measures to further improve the quality of low-carbon management on the basis of the hotel industry, and promote the process of low-carbon hotel industry, accelerate the ecological Hainan the pace of the Ministry of construction for the construction of a socialist harmonious society contribute our respective strength.

\section{References}

[1] Wang Qiuna, Geng Jing, Huang Jianhong. Hotel industry development of low carbon government-led incentives System--A Case Study of Hainan star hotel, Hainan Finance, 2014(10):23-29. 
[2] Liu Yi. Chinese hotel industry the level of energy consumption and carbon Management Approaches, Tourism Tribune, 2012, 27(1):83-90.

[3] Wang Qiuna. Situation Development of low-carbon Hainan hotel industry, Green Technology, 2014(12):249-252,254.

[4] Yan Wenjie, Kong Dehui. Path of development of low-carbon low-carbon economy hotel industry in Heilongjiang, Harbin Vocational and Technical College Journal, 2015(1):98-98,121.

[5] Yin Qifeng. Opportunities and challenges facing China's hotel industry under the background of low-carbon economy, Productivity study, 2011(8):69-70. 